\title{
Investigation on the effects of carbon monoxide contamination towards PEMFC transport phenomena using a kinetics-transport bridging model
}

\author{
Saiful HASMADY* and Kazuyoshi FUSHINOBU* \\ * Department of Mechanical and Control Engineering, Tokyo Institute of Technology \\ 2-12-1 Ookayama, Meguro-ku, Tokyo 152-8552, Japan \\ E-mail: saiful.h.ab@m.titech.ac.jp
}

Received 29 September 2014

\begin{abstract}
This paper reports a numerical study on the effects of $\mathrm{CO}$ contamination towards the distribution of chemical species, surface coverage, current density and temperature inside a PEMFC using a kinetics-transport bridging model. Bridging is done by linking macro-scale, macro-homogeneous transport phenomena models with micro-scale contamination kinetics model via conversion of the surface concentration of the reactants on the rough electrocatalyst into surface site coverage of the participating adsorbates using Langmuir-Freundlich isotherm. The effects of $\mathrm{CO}$ contamination is investigated by solving the bridged model iteratively under steady state, single phase and non-isothermal conditions in three-dimensions. The effect of $\mathrm{CO}$-ad presence on the electrocatalyst surface towards distribution of chemical species, current density and temperature is discussed at cell temperature of $70^{\circ} \mathrm{C}$ and two nominal current densities of 0.5 and $1.0 \mathrm{~A} / \mathrm{cm}^{2}$. The results show that the region under the ribs at anode catalyst layer registered higher magnitude of current density due to blockage from CO-ad under channel. The anode catalyst layer also shows an increase in local temperature comparable to the cathode catalyst layer that can aggravate dehydration of the membrane, which in turn affect its durability in long-term operation.
\end{abstract}

Key words: PEMFC, CO contamination, Langmuir-Freundlich isotherm, Electrochemical kinetics, Adsorption

\section{Introduction}

The recent concern on the over-dependency of fossil fuels and its impact towards global energy economics and environmental problems has sparked interest in efficient energy converters having high power density and near-zero greenhouse gas emission. Fitting this requirements, proton exchange membrane fuel cell (PEMFC) is a promising candidate that can be used not only as a mobile power source in the transportation sector, but also as a stationary power generation system in the distributed energy sector. In its practical usage, a PEMFC operates on humidified hydrogen gas $\left(\mathrm{H}_{2}\right)$ as fuel continuously supplied to the anode electrode, and humidified air consisting oxygen $\left(\mathrm{O}_{2}\right)$ as oxidant to the cathode electrode. The disadvantage of this requirement is the source of $\mathrm{H}_{2}$, in which at present still depends mainly on the product of steam reforming of fossil fuel, usually from methane. Not only the underlying issue of fossil fuel dependency is still not entirely being addressed, $\mathrm{H}_{2}$ obtained from reforming process may contain traces of carbon monoxide (CO) contaminant. Many studies show that traces of $\mathrm{CO}$ in the anode fuel feed, even in ppm, when in contact and reacted within the electrocatalyst of the cell will cause degradation of performance and ultimately lower its long-term durability, as reviewed in $\mathrm{Li}$ (2006). This severe performance loss is found due to CO molecular adsorbate $(\mathrm{CO}-\mathrm{ad})$ on the heterogeneous electrode catalyst decreasing available active Pt catalyst sites needed for the anode hydrogen oxidation reaction (HOR) resulting to a severe kinetic loss and performance deterioration. The large negative change in Gibbs free energy of adsorption of $\mathrm{CO}$ on $\mathrm{Pt}$ for temperatures below $150^{\circ} \mathrm{C}$ leads to its noticeably high coverage compared to other adsorbates such as $\mathrm{H}_{2}$ (Gottesfeld and Pafford, 1988). This situation can be further complicated by the possibility of CO-ad electrochemically oxidizing to form $\mathrm{CO}_{2}$ if the electrode is sufficiently 
polarized to its oxidizing potential (Gilman, 1964).

A comprehensive PEMFC model needs to bridge electrochemical kinetics and transport phenomena in different spatial scales, in which the authors have attempted for a non-isothermal, three-dimensional, single-phase case with no contamination present (Hasmady and Fushinobu, 2009). In particular with fuel cell contamination-related problems, the electrochemical kinetics is important and should be focused, but the physical phenomena of reactant transport in a complex PEMFC geometry should not be left overlooked. Therefore finding a sufficiently physical contamination kinetics model to couple with largely-applied macro-homogeneous transport models is essential to quickly predict the extent of damage to the cell performance, normally quantified by its loss in potential. Though a wealth of data can be found with respect to experimental investigation of $\mathrm{CO}$ contamination, modeling and computational studies that fit the above-mentioned criteria are left less explored. A one-dimensional steady state modeling of PEMFC anode reaction kinetics under reformate feed has been attempted by Springer, et al. (2001). Though this isothermal model is referred to as a pioneering developmental work in CO-contamination modeling, focus is only on the anode electrode to which the overall IV curve is obtained by converting the anode model to a cell model from an empirical equation, instead of modeling the dynamics of whole cell. Since only linear-bonded sites is considered their work, subsequent extension to the model is made by Camara, et al. (2002), who exclusively modeled anode electrode contamination kinetics with the additional inclusion of bridge-bonded adsorption sites of $\mathrm{CO}$ on Pt. A parametric value of $f$ is assigned as the fraction of bridge-bonded sites, and the fraction of linear-bonded sites is defined as $1-f$. The bridge-bonded sites are found from the kinetic fit to the cell anode overpotential experimental data to be $10 \%$ of the overall active sites. Bhatia and Wang (2004) developed transient model for CO contamination kinetics, in which their one-dimensional model is used to investigate effects of different hydrogen dilution. These early modeling works largely concentrated on one-dimensional anode kinetic model, instead of comprehensively modeling and solving transport properties variation in the cell. Not many efforts have been done in bridging transport phenomena to the modeled electrode reaction kinetics. Nevertheless relevant work can be seen in Baschuk and Li (2003) on modeling two-dimensional anode reaction kinetics with oxygen bleeding effect for performance recovery, though the work is concentrated only on the anode side of the cell. Zhou and Liu (2004) as well as Ju, et al. (2008), implemented the kinetic model developed by Springer in their three- and two-dimensional transport model, however some issues in their validation work still prevailed. To the best of the authors' knowledge, multiphase transport phenomena are left unexplored.

A CO contamination electrochemical kinetics model has been developed by the authors, which take into account for the first time statistically the heterogeneity in the binding site energetics (Hasmady and Fushinobu, 2014). In this study, by bridging this kinetics model with largely applied macro-homogeneous transport models, extended investigation on the effects $\mathrm{CO}$ contamination towards the distribution of chemical species, surface coverage, current density and temperature can be attempted. A single-phase, three-dimensional, non-isothermal and steady state

(a)

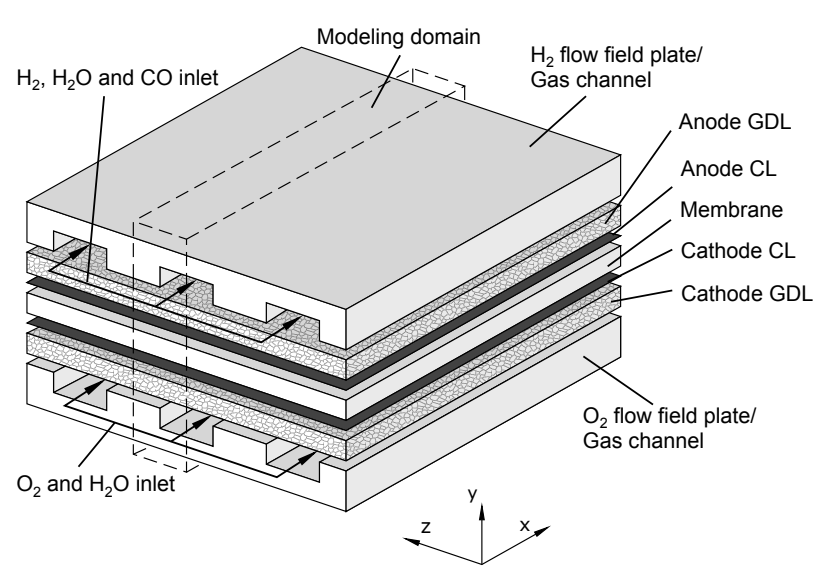

(b)

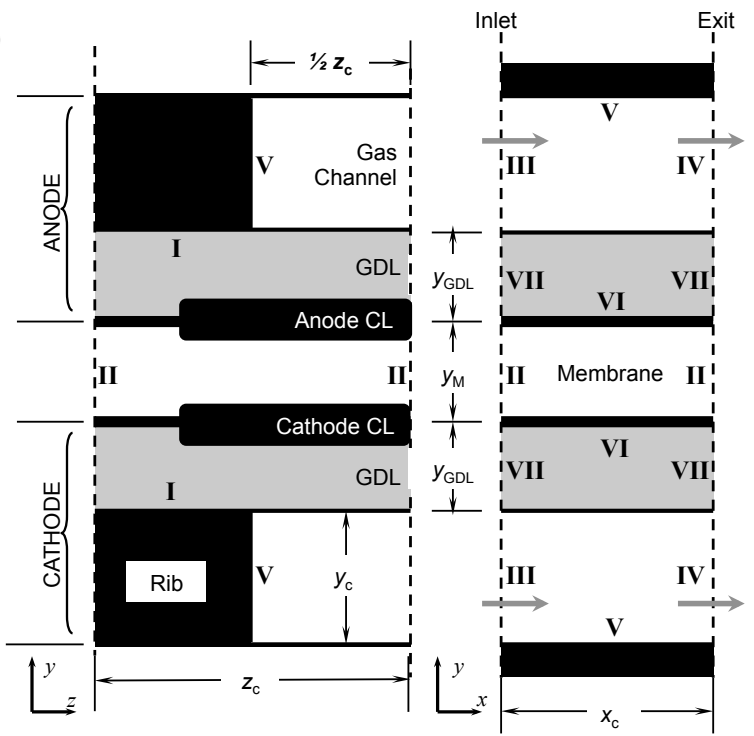

Fig. 1 (a) Three-dimensional view of the single-cell PEMFC studied with the region enclosed by the dashed lines is the single channel, parallel co-flow modeling domain, and (b) detailed view of the modeling schematic and boundary conditions, taking into account symmetry condition along $y$-axis. 
Table 1 Experimental parameters (Lee, et al., 1999).

\begin{tabular}{l|c}
\hline \hline \multicolumn{1}{c|}{ Parameter } & Value \\
\hline Operating & \\
Cell temperature $\left[{ }^{\circ} \mathrm{C}\right]$ & $40,55,70,85$ \\
Pressure $[\mathrm{kPa}]$ & 100 \\
Relative humidity [\%] & 100 \\
Bulk CO concentration [ppm] & $5,20,50,100$ \\
Construction & \\
Catalyst loading $\left[\mathrm{mg}_{\mathrm{Pt}} / \mathrm{cm}^{2}\right]$ & 0.4 \\
Geometric area $\left[\mathrm{cm}^{2}\right]$ & 5 \\
Membrane thickness $[\mathrm{mm}]$ & 0.127 \\
\hline
\end{tabular}

conditions are chosen for the macro-homogeneous transport model. By solving iteratively the bridged models, the superficial coverage of the participating adsorbates on the electrocatalysts can be found. This in turn allows for qualitative and quantitative investigation on the distribution of the chemical species, current density and temperature in an operating cell. Discussions on how the results may affect the loss in performance as well as durability of the cell is subsequently presented.

\section{Governing Equations}

Three-dimensional construction of a typical PEMFC is depicted in Fig. 1 (a) (Hasmady and Fushinobu, 2014). The operating parameters are chosen to match the experimental cell of Lee, et al. (1999). The PEMFC modeled in this work is a single cell with parallel gas channels separated by ribs, clamped together to gas diffusion electrodes loaded with $\mathrm{Pt}$ nanoparticles (Vulcan XC72, E-TEK) sandwiched in between an ionomer membrane (Nafion). The dimensions are shown in Fig. 1 (b), and the operating conditions are tabulated in Table 1, which are the actual experimental conditions as reported (Lee, et al., 1999). Humidified reformate hydrogen gas with variable CO concentrations [ppm] and humidified oxygen gas are supplied in the anode and cathode gas flow field, respectively. The reactants gas species are transported in the flow field plates through the parallel channels arranged in co-flow. A volumetric flow rate of $50 \mathrm{sccm}$ is set for both reactants to ensure high reaction stoichiometry for the whole range of operation. The list of assumptions made in this work includes:

- The gas mixture obeys ideal gas law and its flow is steady, laminar and incompressible.

- Water is saturated in vapor phase.

- The catalyst layers are treated as a two-dimensional planar interface in between GDL and membrane consisting of void, ionomer and solid Pt supported on carbon.

- The gas diffusion layer (GDL) is made from a material that is isotropic and homogeneous.

- Electrical contact resistance at the all interfaces is negligible.

- The solid and fluid phases are in thermal equilibrium over the GDL porous structure.

The steady state, three-dimensional and single phase governing equations for the conservation of mass, momentum, chemical species, charge and energy within the calculation domain can be written as

Conservation of mass

$\nabla \cdot(\varepsilon \rho \mathbf{u})=0$

Conservation of momentum

$$
\nabla \cdot(\varepsilon \rho \mathbf{u u})=-\varepsilon \nabla p+\nabla \cdot\left(\mu^{\mathrm{eff}} \nabla \mathbf{u}\right)+S_{\text {mom }}
$$

Conservation of chemical species

$$
\nabla \cdot\left(\varepsilon c \mathbf{u} X_{i}\right)=c \sum_{i=1}^{n-1} \nabla \cdot\left(D_{i j}^{\mathrm{eff}} \nabla X_{i}\right)+S_{\mathrm{spe}, i} \text { with } \sum_{i=1}^{n} X_{i}=1
$$

Conservation of electronic and ionic charge

$$
\nabla \cdot\left(\sigma_{\mathrm{s}}^{\mathrm{eff}} \nabla \phi_{\mathrm{s}}\right)+S_{\mathrm{ch,s}}=0 \text {, and } \nabla \cdot\left(\sigma_{\mathrm{p}}^{\mathrm{eff}} \nabla \phi_{\mathrm{M}}\right)+S_{\mathrm{ch}, \mathrm{M}}=0
$$

Conservation of energy 


$$
\left(\rho c_{\mathrm{p}}\right)^{\mathrm{eff}}(\mathbf{u} \cdot \nabla T)=\nabla \cdot\left(k^{\mathrm{eff}} \nabla T\right)+S_{\text {ene }}
$$

Detailed description of the conservation equations and their volumetric source terms has already been published elsewhere (Hasmady and Fushinobu, 2014) and is omitted here for brevity. Nevertheless, the transport parameters and relevant constitutive relations are summarized in Table 2.

\subsection{Formulation of Bridging Electrochemical Kinetics}

For both electrodes, heterogeneous half-cell electrochemical reactions occur at the active sites. Active sites are defined as locations in the catalyst layer where Pt, ionomer and gas phase are in contact, namely a three-phase boundary.

\subsubsection{Anode HOR under CO Contamination}

For the case of anode, the model starts with the basis that there are two competing reactions taking place, the HOR, and $\mathrm{CO}$ oxidation reaction (COR). In overall, the reaction mechanism consists of a total of 5 reactions written according to the steps outlined below, numbered consecutively as Rna

Competitive adsorption:

$$
\begin{aligned}
& \mathrm{H}_{2}+2 \mathrm{Pt} \underset{k_{1 \mathrm{~b}}}{\stackrel{k_{14}}{\leftrightarrows}} 2 \mathrm{Pt}-\mathrm{H} \\
& \mathrm{CO}+\mathrm{Pt} \underset{k_{2 \mathrm{~b}}}{\stackrel{k_{25}}{\leftrightarrows}} \mathrm{Pt}-\mathrm{CO}
\end{aligned}
$$

HOR:

$$
\mathrm{Pt}-\mathrm{H} \underset{k_{3 \mathrm{~b}}}{\stackrel{k_{3 \mathrm{f}}}{\longrightarrow}} \mathrm{Pt}+\mathrm{H}^{+}+\mathrm{e}^{-}
$$

COR:

$$
\begin{array}{ll}
\mathrm{H}_{2} \mathrm{O}+\mathrm{Pt} \underset{k_{4 \mathrm{~b}}}{\stackrel{k_{4 \mathrm{f}}}{\longrightarrow}} \mathrm{Pt}-\mathrm{H}_{2} \mathrm{O} & \text { (fast) } \\
\mathrm{Pt}-\mathrm{CO}+\mathrm{Pt}-\mathrm{H}_{2} \mathrm{O} \stackrel{k_{5 \mathrm{f}}}{\longrightarrow} 2 \mathrm{Pt}+\mathrm{CO}_{2}+2 \mathrm{H}^{+}+2 \mathrm{e}^{-} \quad \text { (fast) }
\end{array}
$$

On anode Pt active site, the summation of the coverage of individual adsorbates from mechanism above is unity

$$
\theta_{\mathrm{H}}+\theta_{\mathrm{CO}}+\theta_{\mathrm{Pt}}=1
$$

The constraint imposed in Eq. (6) together with the rate expressions of the each individual step above leads to the following equations, obtained by which after employing the Langmuir-Freundlich (L-F) isotherm (Sips, 1948) allows for calculation of the individual surface coverage of the adsorbates as a function of the equilibrium constant of each reaction step $K_{\mathrm{R} n a}$, surface partial pressure of the gas species $P_{i}$ and the heterogeneity index $h$,

$$
\theta_{\mathrm{H}}=\frac{1}{B_{\mathrm{a}}} \sqrt{\left(K_{\mathrm{R} 1 \mathrm{a}} P_{\mathrm{H}_{2}}\right)^{h}}, \theta_{\mathrm{CO}}=\frac{1}{B_{\mathrm{a}}}\left(K_{\mathrm{R} 2 \mathrm{a}} P_{\mathrm{CO}}\right)^{h}, \theta_{\mathrm{Pt}}=\frac{1}{B_{\mathrm{a}}}
$$

where $\quad B_{\mathrm{a}}=1+\sqrt{\left(K_{\mathrm{R} 1 \mathrm{a}} P_{\mathrm{H}_{2}}\right)^{h}}+\left(K_{\mathrm{R} 2 \mathrm{a}} P_{\mathrm{CO}}\right)^{h}$

The heterogeneity index in the L-F isotherm, having a value between zero and unity is proposed to be used in this work due to the fact that rough electrode is used in PEM fuel cells, which implies heterogeneous surface active site binding energetics. An $h$ value of unity means the surface is smooth and having a homogeneous binding site energetics, reverting the L-F isotherm to the widely applied Langmuir isotherm.

The data in Eq. (7) can be found in Hauptmann, et al. (2011) that is thermodynamically optimized and takes into account adsorbate-adsorbate interactions by having the activation energy $\tilde{E}_{\mathrm{a}}$ a function of adsorbate coverage.

The local current density at the anode catalyst layer is obtained from the summation of the dual currents originating from the concurrent HOR and COR in which in this work is derived to be a function of total anode activation overpotential $\eta_{\mathrm{a}}$ in the following expression (Hasmady and Fushinobu, 2014) where $f=F / R T$,

$$
i_{\mathrm{a}}=2 i_{0, \mathrm{H}}\left(1-\frac{i_{\mathrm{a}}}{i_{\mathrm{Lim}}}\right) \sinh \left(\alpha f \eta_{\mathrm{a}}\right)+i_{0, \mathrm{CO}}^{\text {eff }} \theta_{\mathrm{CO}} \theta_{\mathrm{H}_{2} \mathrm{O}} \exp \left(\alpha f \eta_{\mathrm{a}}\right)
$$

where the limiting current density due to blockage of $\mathrm{CO}$ adsorbates on available active sites is proposed to be 


$$
i_{\mathrm{Lim}}=2 F s_{1} \sqrt{\frac{R T}{2 \pi M_{\mathrm{H}_{2}}}}\left(\frac{T}{T_{0}}\right)^{\beta_{1 \mathrm{ff}}} c_{\mathrm{H}_{2}}\left(1-\theta_{\mathrm{CO}}\right)^{2}
$$

The anode activation overpotential is calculated simply by algebraic manipulation of Eq. (8).

\subsubsection{Cathode ORR}

The actual mechanism for the ORR in PEMFC is still being debated. In this work, the dissociative mechanism (Zhdanoz and Kasemo, 2006) is chosen due to the availability of kinetic data as follows

$$
\begin{array}{ll}
\mathrm{O}_{2}+2 \mathrm{Pt} \underset{k_{1 \mathrm{~b}}}{\stackrel{k_{\mathrm{ff}}}{\leftrightarrows}} 2 \mathrm{Pt}-\mathrm{O} & \text { (fast) } \\
\mathrm{Pt}-\mathrm{O}+\mathrm{H}^{+}+\mathrm{e}^{-} \underset{k_{2 \mathrm{~b}}}{\stackrel{k_{25}}{\leftrightarrows}} \mathrm{Pt}-\mathrm{OH} & \text { (RDS) } \\
\mathrm{Pt}-\mathrm{OH}+\mathrm{H}^{+}+\mathrm{e}^{-} \underset{k_{3 \mathrm{f}}}{\stackrel{k_{3 \mathrm{~b}}}{\leftrightarrows}} \mathrm{Pt}-\mathrm{H}_{2} \mathrm{O} \\
\mathrm{Pt}-\mathrm{H}_{2} \mathrm{O} \underset{k_{4 \mathrm{~b}}}{\stackrel{k_{45}}{\longrightarrow}} \mathrm{Pt}+\mathrm{H}_{2} \mathrm{O}
\end{array}
$$

The summation of surface coverage on Pt, is then simply $\theta_{\mathrm{O}}+\theta_{\mathrm{OH}}+\theta_{\mathrm{H}_{2} \mathrm{O}}+\theta_{\mathrm{Pt}}=1$

The surface coverage on cathode Pt can be written independently as a function of surface partial pressure of gases by applying L-F isotherm

$$
\begin{aligned}
& \left.\theta_{\mathrm{O}}=\frac{1}{B_{\mathrm{c}}} \sqrt{\left(K_{\mathrm{RIc}} P_{\mathrm{O}_{2}}\right)^{h}}, \theta_{\mathrm{OH}}=\frac{1}{B_{\mathrm{c}}}\left[\frac{P_{\mathrm{H}_{2} \mathrm{O}}}{K_{\mathrm{R} 3 \mathrm{c}}} e^{f\left(E_{\mathrm{c}}-E_{\mathrm{c}}^{\ominus}\right.}\right)\right]^{h}, \theta_{\mathrm{H}_{2} \mathrm{O}}=\frac{1}{B_{\mathrm{c}}}\left(\frac{P_{\mathrm{H}_{2} \mathrm{O}}}{K_{\mathrm{R} 3 \mathrm{c}}}\right)^{h} \text { and } \theta_{\mathrm{P}_{\mathrm{t}}}=\frac{1}{B_{\mathrm{c}}} \\
& \text { Where } B_{\mathrm{c}}=1+\sqrt{\left(K_{\mathrm{R} 1 \mathrm{c}} P_{\mathrm{O}_{2}}\right)^{h}}+\left[\frac{P_{\mathrm{H}_{2} \mathrm{O}}}{K_{\mathrm{R} 3 \mathrm{c}}} e^{f\left(E_{\mathrm{c}}-E_{\mathrm{c}}^{\ominus}\right)}\right]^{h}+\left(\frac{P_{\mathrm{H}_{2} \mathrm{O}}}{K_{\mathrm{R} 3 \mathrm{c}}}\right)^{h}
\end{aligned}
$$

The equilibrium constants are calculated in the same way as anode, using data from Hauptmann, et al. (2011). The cathode local cathode current density is written originating from the slowest step R2c as

$$
i_{\mathrm{c}}=i_{0, \mathrm{c}}\left[\frac{\theta_{\mathrm{O}}}{\theta_{\mathrm{O}}^{*}} e^{-\alpha f \eta_{\mathrm{c}}}-\frac{\theta_{\mathrm{OH}}}{\theta_{\mathrm{OH}}^{*}} e^{(1-\alpha) f \eta_{\mathrm{c}}}\right]
$$

By defining $\delta_{+}=-\left[\left(\theta_{\mathrm{O}} / \theta_{\mathrm{O}}^{*}\right)+\left(\theta_{\mathrm{OH}} / \theta_{\mathrm{OH}}^{*}\right)\right]$ and $\delta_{-}=\left(\theta_{\mathrm{O}} / \theta_{\mathrm{O}}^{*}\right)-\left(\theta_{\mathrm{OH}} / \theta_{\mathrm{OH}}^{*}\right)$, the cathode activation overpotential is written by rearranging Eq. (12) into a closed-form galvanostatic form as

$$
\begin{aligned}
& \eta_{\mathrm{c}}=\frac{R T}{F}\left(\xi_{\mathrm{c}}-\gamma_{\mathrm{c}}\right) \\
& \text { If } \delta_{+}<\left|\delta_{-}\right|, \quad \xi_{\mathrm{c}}=\cosh ^{-1}\left(\frac{i_{\mathrm{c}}}{i_{0, \mathrm{c}} \Lambda_{\mathrm{c}}}\right), \Lambda_{\mathrm{c}}=2 \sqrt{\left(\frac{\theta_{\mathrm{O}}}{\theta_{\mathrm{O}}^{*}}\right)\left(\frac{\theta_{\mathrm{OH}}}{\theta_{\mathrm{OH}}^{*}}\right)}, \text { and } \gamma_{\mathrm{c}}=\tanh ^{-1}\left(\frac{\delta}{\delta_{+}}\right) \\
& \text {And if }\left|\delta_{+}\right|>\delta_{-}, \quad \xi_{\mathrm{c}}=\sinh ^{-1}\left(\frac{i_{\mathrm{c}}}{i_{0, \mathrm{c}} \Lambda_{\mathrm{c}}}\right), \Lambda_{\mathrm{c}}=2 \sqrt{\left(\frac{\theta_{\mathrm{O}}}{\theta_{\mathrm{O}}^{*}}\right)\left(\frac{\theta_{\mathrm{OH}}}{\theta_{\mathrm{OH}}^{*}}\right)}, \text { and } \gamma_{\mathrm{c}}=\tanh ^{-1}\left(\frac{\delta_{+}}{\delta_{-}}\right)
\end{aligned}
$$

\section{Boundary Conditions}

The boundaries of the modeling domain can be referred to Fig. 1 (b) marked with Roman numerals. A fixed-value of $T$ and $\phi_{\mathrm{s}}$ is applied at boundary $\mathbf{I}$, in which the $\phi_{\mathrm{s}}$ is calculated from the anode/cathode potential updated iteratively by $T=T_{\text {cell }}, \phi_{\mathrm{s}, \mathrm{c}}=E_{\mathrm{c}}$ and $\phi_{\mathrm{s}, \mathrm{a}}=E_{\mathrm{a}}$. Symmetry boundary conditions are applied along boundary II for all variables. At inlet boundary III, a fixed value of $\mathbf{u}, X_{i}$ and $T$ is applied by $u_{x}=u_{\text {in }}, u_{y}=0, u_{z}=0, X_{i}=X_{i \text {,in }}$ and $T=T_{\text {cell. }}$ Here, $u_{\text {in }}$ is calculated from using the inlet volume flow rate $\dot{\forall}$ simply as $u_{\text {in }}=\dot{\forall} / A_{\text {ch }}$, where $A_{\text {ch }}$ is the channel inlet cross-sectional area. The inlet mole fraction $X_{i \text {,in }}$ for the anode and cathode is calculated from the information of its inlet relative humidity $\varphi_{\mathrm{a} / \mathrm{c}}$ as 
Table 2 Transport correlations, kinetics correlations and constitutive relations in this work.

\begin{tabular}{|c|c|}
\hline Parameter & Expression \\
\hline Transport & \\
\hline Gas mixture molar density & $\rho_{\mathrm{m}}=P M_{\mathrm{avg}} / R T$ \\
\hline Gas mixture average molecular weight & $M_{\mathrm{avg}}=\sum_{i} X_{i} M_{i}$ \\
\hline Saturation pressure & $\log _{10} P_{\text {sat } @ T}=2.95 \times 10^{-2}(T-273)-9.18 \times 10^{-5}(T-273)^{2}+1.44 \times 10^{-7}(T-273)^{3}-2.18$ \\
\hline Membrane hydration (Springer, et al. & $\int 0.043+17.18 a-39.85 a^{2}+36 a^{3} \quad 0 \leq a \leq 1$ \\
\hline 1991) & $\lambda=\{\quad 14+1.4(a-1)$ \\
\hline Water activity (Springer, et al. 1991) & $a=P_{\mathrm{v}} / P_{\mathrm{sat}}$ \\
\hline $\begin{array}{l}\text { Protonic conductivity (Springer, et al. } \\
\text { 1991) }\end{array}$ & $\sigma_{\mathrm{p}}=(0.005139 \lambda-0.00326) \exp \left[1268\left(\frac{1}{303}-\frac{1}{T}\right)\right]$ \\
\hline Effective binary diffusivity & $D_{i j}^{e f f}=f(\varepsilon) \cdot D_{i j}$ where $f(\varepsilon)=\varepsilon^{1.5}$ \\
\hline Effective heat capacity & $\left(\rho c_{p}\right)^{\mathrm{eff}}=(1-\varepsilon) \rho_{\mathrm{s}} c_{p, \mathrm{~s}}+\varepsilon \rho_{\mathrm{m}} c_{p, \mathrm{~m}}$ \\
\hline Solid phase specific heat (Zamel, 2011) & $c_{p, \mathrm{~s}}=\mathrm{wt} \%_{\mathrm{C}} c_{p, \mathrm{c}}+\mathrm{wt} \%_{\mathrm{PTFE}} c_{p, \mathrm{PTFE}}$ \\
\hline Carbon specific heat (Zamel, 2011) & $c_{p, \mathrm{C}}=1.06 \times 10^{-6}(T-273)^{3}-2.98 \times 10^{-3}(T-273)^{2}+3.2(T-273)+639.66$ \\
\hline PTFE specific heat (Zamel, 2011) & $c_{p, \mathrm{PTFE}}=4(T-273)+1000$ \\
\hline Gas mixture specific heat & $c_{p, \mathrm{~m}}=\sum_{i} X_{i} c_{p, i}$ \\
\hline Gas specific heat (Masuda, 2003) & $\begin{array}{l}c_{p, \mathrm{H} 2}=27.28-1.92 \times 10^{-3} T+5.0 \times 10^{4} / T^{2} \\
c_{p, \mathrm{O} 2}=29.96+1.52 \times 10^{-2} T-1.67 \times 10^{5} / T^{2} \\
c_{p, \mathrm{H} 2 \mathrm{O}}=30.54+10.29 T+1 / T^{2}\end{array}$ \\
\hline Effective thermal conductivity & $k^{\mathrm{eff}}=(1-\varepsilon) k_{\mathrm{s}}+\varepsilon k_{\mathrm{m}}$ \\
\hline $\begin{array}{l}\text { Gas thermal conductivity (Masuda, } \\
\text { 2003) } \\
\text { Kinetics }\end{array}$ & $k_{\mathrm{H} 2}=2.49 \times 10^{-3} T^{0.752}, k_{\mathrm{O} 2}=2.23 \times 10^{-4} T^{0.839}, k_{\mathrm{H} 2 \mathrm{O}}=2.5 \times 10^{-6} T^{1.56}$ \\
\hline Roughness factor & $r_{\mathrm{f}}=L_{\mathrm{Pt}} A_{\mathrm{r}}$ \\
\hline $\begin{array}{l}\text { Forward rate constant (Hauptmann, et } \\
\text { al., 2011) }\end{array}$ & $k_{n \mathrm{f}}=\frac{s_{n}}{\Gamma^{m}} \sqrt{\frac{R T}{2 \pi M_{i}}}\left(\frac{T}{T_{0}}\right)^{\beta n \mathrm{f}} \exp \left(-\frac{\tilde{E}_{\mathrm{a}, n \mathrm{f}}(\theta)}{R T}\right)$ \\
\hline $\begin{array}{l}\text { Backward rate constant (Hauptmann, et } \\
\text { al., 2011) }\end{array}$ & $k_{n \mathrm{~b}}=\frac{A_{n}}{\Gamma^{m-1}}\left(\frac{T}{T_{0}}\right)^{\beta n \mathrm{~b}} \exp \left(-\frac{\tilde{E}_{\mathrm{a}, n \mathrm{~b}}(\theta)}{R T}\right)$ \\
\hline Equilibrium constant & $K_{n}=k_{n \mathrm{f}} / k_{n \mathrm{~b}}$ \\
\hline $\begin{array}{l}\text { CO sticking coefficient (Hasmady and } \\
\text { Fushinobu, 2014) }\end{array}$ & $s_{1}=s_{0} \exp \left(-\frac{\sigma_{1}}{R T}\right)$ \\
\hline Anode reversible potential & $E_{\mathrm{a}}^{\mathrm{rev}}=0$ \\
\hline $\begin{array}{l}\text { Cathode reversible potential (Gurau, et } \\
\text { al., 1998) }\end{array}$ & $E_{\mathrm{c}}^{\mathrm{rev}}=0.0025 T+0.2329$ \\
\hline Anode potential & $E_{\mathrm{a}}=E_{\mathrm{a}}^{\mathrm{rev}}-\frac{1}{A_{\mathrm{CL}}} \int_{\Delta x} \int_{\Delta z}\left|\eta_{\mathrm{a}}\right| d z d x$ \\
\hline Cathode potential & $E_{\mathrm{c}}=E_{\mathrm{c}}^{\mathrm{rev}}-\frac{1}{A_{\mathrm{CL}}} \int_{\Delta x} \int_{\Delta z}\left|\eta_{\mathrm{c}}\right| d z d x$ \\
\hline Ohmic resistance & $R_{\mathrm{ohmic}}=y_{\mathrm{M}} / \sigma_{\mathrm{p}}(\lambda)$ \\
\hline
\end{tabular}


Table $3 S_{\mathrm{CL}}$ values.

\begin{tabular}{l|c|c}
\hline \hline \multicolumn{1}{c|}{ Conservation Equation } & Anode & Cathode \\
\hline Chemical species, Eq. (3) & $-\frac{\overline{i_{\mathrm{a}}}}{2 F}$ for $\mathrm{H}_{2}$ & $-\frac{\overline{i_{\mathrm{c}}}}{4 F}$ for $\mathrm{O}_{2}$ \\
Electronic charge, Eq. (4) & $-\overline{i_{\mathrm{a}}}$ & $\overline{i_{\mathrm{c}}}$ \\
Ionic charge, Eq. (4) & $\overline{i_{\mathrm{a}}}$ & $-\overline{i_{\mathrm{c}}}$ \\
& $-\left(-\frac{T \Delta S_{\mathrm{a}}}{2 F}+\left|\eta_{\mathrm{a}}\right|\right)$ & $\overline{i_{\mathrm{c}}}$ \\
Energy, Eq. (5) & $\left.-\frac{T \Delta S_{\mathrm{c}}}{2 F}+\left|\eta_{\mathrm{c}}\right|\right)$ \\
\hline
\end{tabular}

$$
X_{\mathrm{O}_{2}, \mathrm{in}}=1-\varphi_{\mathrm{c}} \frac{P_{\text {sat } \mathrm{P}_{\mathrm{cull}}}}{P_{\mathrm{c}}}, X_{\mathrm{H}_{2}, \mathrm{in}}=1-\varphi_{\mathrm{a}} \frac{P_{\text {sat } T_{\mathrm{ccll}}}}{P_{\mathrm{a}}}-X_{\mathrm{CO}, \mathrm{in}}
$$

where $X_{\mathrm{CO}, \text { in }}$ is a variable provided as input based on the experimental data available. At outlet boundary $\mathbf{I V}$, zero gradient condition is applied for all variables. No-slip boundary condition is applied for velocity vectors at $\mathbf{V}$ and VII but for scalars, zero-gradient is specified.

Boundary VI is the membrane/catalyst layer interface. The electrochemical reaction here prescribes local fluxes towards the computational nodes at adjacent locations. To do so, the following equation is applied to the node adjacent to the interface

$$
\int_{A} \mathbf{n} \cdot(\mathbf{u} \Phi) d A-\int_{A} \mathbf{n} \cdot(\Psi \nabla \Phi) d A=S_{\mathrm{CL}} \Delta x \Delta z
$$

where $\Phi, \Psi$ and $S_{\mathrm{CL}}$ are arbitrary unknown variable, diffusivity and superficial source term from the conservation equations, respectively. Each conservation equation from (1) to (5) is affected by the catalyst layer flux through flow re-distribution, reactant consumption, local reaction rate and thermal energy release. $S_{\mathrm{CL}}$ depends on the flux of the transport parameters under the effect of local reaction rate, or termed here as local current density based on geometric surface area $\overline{i_{\mathrm{a}}}$ or $\bar{i}_{\mathrm{c}}\left[\mathrm{A} / \mathrm{m}^{2}\right]$. As a note, since rough electrode is used, a roughness factor $r_{\mathrm{f}}$ is defined in this work to be $r_{\mathrm{f}}=L_{\mathrm{Pt}} A_{\mathrm{r}}\left[\mathrm{m}_{\mathrm{Pt}}^{2} / \mathrm{m}^{2}\right]$. This leads to the local current density based on geometric surface area $\bar{i}$ to be related to the local current density based on Pt active site surface area $i\left[\mathrm{~A} / \mathrm{m}_{\mathrm{Pt}}^{2}\right.$ ] by $\bar{i}=i r_{\mathrm{f}}$. The list of $S_{\mathrm{CL}}$ relevant at the catalyst layer is tabulated in Table 3 .

\section{Closing Equations and Numerical Solution Procedure}

The approach adopted in this work is galvanostatic, which means that the model has the ability to compute the anode and cathode overpotential by supplying to the model current density as input. Methodologically, at each electrode, applying a current density input will transcribe a chemical species consumption flux, which in turn dictates using an isotherm the surface coverage of each participating adsorbates based on the chosen set of elementary reactions. The surface coverage, alongside the iteratively calculated local current density allows for computation of the kinetically dependent activation overpotential of each electrode. This gives a computational estimation on how much polarization, or loss in potential the electrode experiences, particularly if the polarization is originating from contamination.

The overall cell potential then is calculated as the difference of the electrode potentials plus an additional loss due to ohmic resistance in the membrane $R_{\text {ohmic }}$

$$
E_{\text {cell }}=E_{\mathrm{c}}-E_{\mathrm{a}}-\bar{i} R_{\text {ohmic }}
$$

The list of the parameters and constants used in this work is omitted in this paper for brevity, and can be found elsewhere in Hasmady and Fushinobu (2014). The coupled transport Eq. (1) - (5) are discretized using finite volume method and solved in three dimensions using an in-house developed computer solver. Convergence is achieved when maximum error in the calculated array field is less than $1.0 \times 10^{-7}$. 


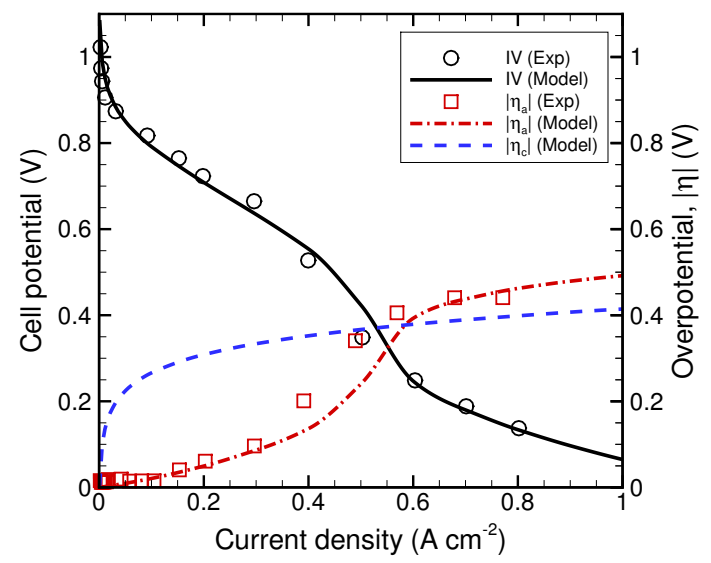

Fig. 2 Polarization curve (solid line), anode overpotential and cathode overpotential plots (dashed lines) for a PEMFC contaminated with 20 -ppm CO concentration at $70^{\circ} \mathrm{C}$.

\section{Results and Discussions}

The results from this model have been validated with experimental data of Lee, et al. (1999) and Oetjen, et al. (1996). Comparison is made with the polarization curves and anode overpotential data sets at various bulk CO concentration and cell temperature, to which excellent agreement is found (Hasmady and Fushinobu, 2014). To aid in the forthcoming discussions, the calculated polarization curve and anode overpotential are plotted in comparison with their respective experimental data from Lee et al. (1999) side-by-side in Fig. 2, for the case of 20 ppm bulk CO concentration and cell temperature of $70^{\circ} \mathrm{C}$. Additionally, the cathode overpotential variation with current density is also plotted in the same figure. From Fig. 2, it is evident that the source of loss in cell potential at low current densities $\left(<0.1 \mathrm{~A} / \mathrm{cm}^{2}\right)$ is the cathode overpotential. Anode overpotential at low current densities remains small enough that it can almost be neglected. However, as current density increases to ca. $0.4-0.6 \mathrm{~A} / \mathrm{cm}^{2}$, the magnitude of anode overpotential increases dramatically. This behavior, in tandem with cathode overpotential, significantly aggravates the total loss in cell potential. The anode overpotential profile also shows a plateauing region when the current density is higher than ca. $0.6 \mathrm{~A} / \mathrm{cm}^{2}$, which is attributed to oxidation of CO-ad from COR. It is worth mentioning that COR will only take place once the anode potential reaches a certain value, normally in the range of $0.5-0.9 \mathrm{~V}$ depending on the electrode temperature. It is reported in Kawaguchi, et al. (2004) that higher electrode temperature will cause the onset of CO-ad oxidation will occur at even lower potentials.

Figure 3 shows the through-plane distribution of gas species mole fraction calculated in this work by taking into account conservation of multi-component chemical species. This figure shows a qualitative snapshot of the distribution halfway along the channel when the cell is operated under a continuous supply of 20 -ppm bulk $\mathrm{CO}$ concentration, $70^{\circ} \mathrm{C}$ cell temperature and $0.5 \mathrm{~A} / \mathrm{cm}^{2}$ applied current density. The fact that current is drawn from the cell implies a reaction rate-prescribed molar consumption flux exists at the catalyst layer. For clarity, a catalyst layer here is referred to the

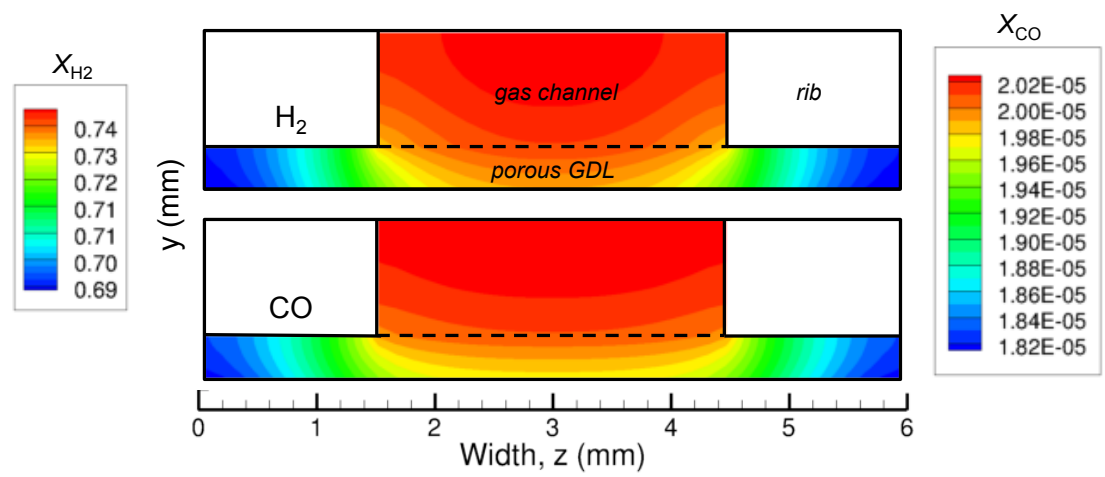

Fig. 3 Through-plane distribution of mole fraction of $\mathrm{H}_{2}$ (top) and $\mathrm{CO}$ (bottom) at anode for the case of 20-ppm bulk $\mathrm{CO}$ concentration, $70^{\circ} \mathrm{C}$ and $0.5 \mathrm{~A} / \mathrm{cm}^{2}$ halfway along the channel. 

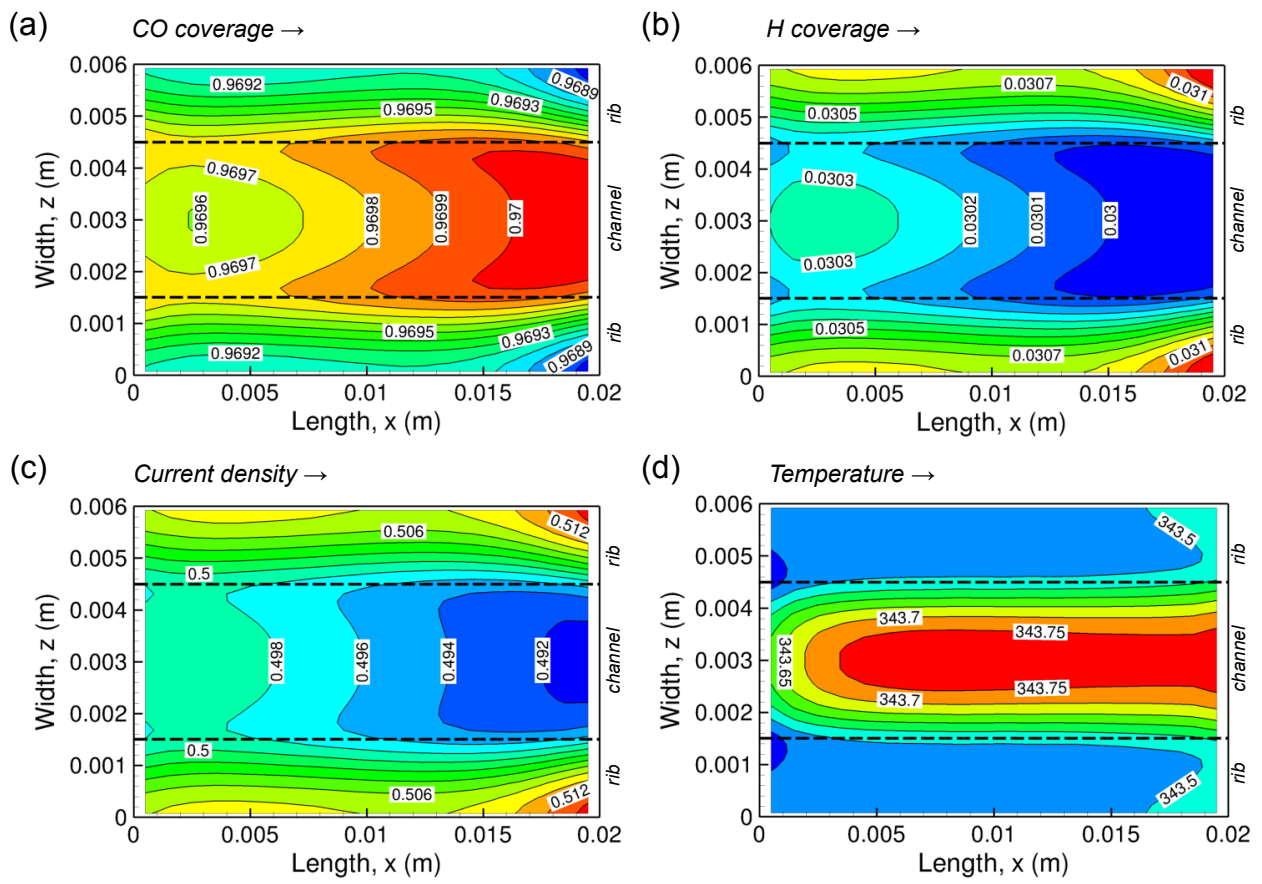

Fig. 4 In-plane distribution of (a) $\mathrm{CO}$ surface coverage, (b) $\mathrm{H}$ surface coverage, (c) current density, and (d) temperature, at anode catalyst layer/membrane interface for the case of 20 -ppm bulk $\mathrm{CO}$ concentration, $70^{\circ} \mathrm{C}$ and $0.5 \mathrm{~A} / \mathrm{cm}^{2}$. Arrow indicates flow direction.

interface between porous GDL and membrane. It is obvious in Fig. 3 that the molar consumption flux from HOR will result into the mole fraction of $\mathrm{H}_{2}$ decreasing towards the anode catalyst layer. The region under the ribs has a comparatively lower mole fraction compared to the region under the channel due to the geometry of the cell leads to the gas species to be transported following the path of least resistance. The same trend is observed for CO, however, the difference is that the molar consumption flux of CO is dictated by the rate of COR at the anode catalyst layer. Since the magnitude of $\mathrm{CO}$ oxidation rate is significantly lower than the rate of HOR, a smaller concentration gradient can be seen from how CO is distributed. Based on this figure, the surface mole fraction of the gas species is known and is used as an input to obtain the coverage of the adsorbates participating in the HOR, COR and also ORR reaction mechanism.

From the information on the surface mole fraction of the gas species obtained in Fig. 3, a qualitative comparison on the coverage of the main adsorbates participating in the anode reaction mechanism can be made. Figure 4 (a) shows the in-plane surface coverage distribution of $\mathrm{CO}$-ad at the anode catalyst layer under the conditions similar to the one applied in Fig. 3. It can be seen that for the region directly under channel, CO-ad coverage is increasing towards exit. This can be explained as when current is drawn from the cell, the region where onset of $\mathrm{CO}$ oxidation reaction occurring would be around the vicinity of channel inlet. This will impose a region of low CO-ad coverage under channel near inlet since CO-ad here is converted into products of COR. Consequently, the region where the CO-ad coverage is lowest would be under the ribs near exit. This is explained by less amount of CO gas species reach this area due to transport resistance. On the other hand, the in-plane distribution of the competitively participating H-ad is shown in Fig. 4 (b). Under channel, it can be seen that the $\mathrm{H}$-ad coverage decreasing towards exit. However, a comparatively higher $\mathrm{H}$-ad coverage is found under the ribs, with the region with highest coverage of $\mathrm{H}$-ad is shown to be directly under the ribs near exit. It is worth mentioning that the distribution of $\mathrm{H}$-ad does not follow the distribution of mole fraction of $\mathrm{H}_{2}$ due to the competitive presence of $\mathrm{CO}$. The higher binding affinity $\mathrm{Pt}$ has with respect to $\mathrm{CO}$ causes $\mathrm{CO}$-ad to be preferentially adsorbed under the channel, limiting $\mathrm{H}$-ad sites at this location. The H-ad coverage distribution directly translates into the anode current density distribution viewable in Fig. 4 (c), where the region under the ribs has higher current density compared to the region under the channel. Also, the highest current density is found directly under the ribs near exit. Additional investigation is done with respect to the distribution of temperature at the anode catalyst layer surface in Fig. 4 (d). Under channel, the temperature is predicted to be increasing towards the exit, due to the simultaneous effect of surface heat flux and reactant flow direction. The region under the ribs is predicted to have a slightly lower temperature compared to under channel, with a small increment of temperature is seen at exit. 
(a)

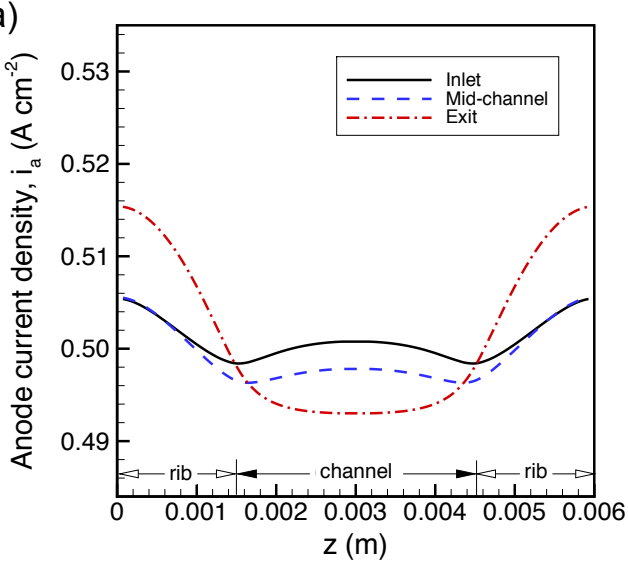

(b)

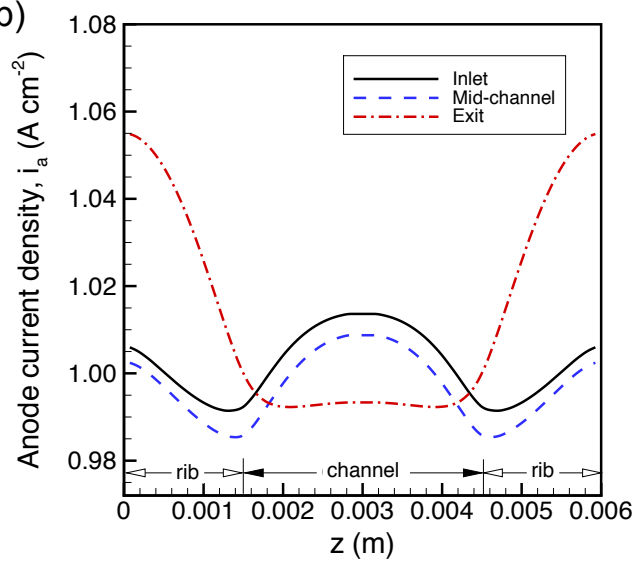

Fig. 5 Comparison of anode current density distribution at catalyst layer/membrane interface at three different locations along the channel at $20 \mathrm{ppm}, 70^{\circ} \mathrm{C}$, and current densities of (a) $0.5 \mathrm{~A} / \mathrm{cm}^{2}$, and (b) $1.0 \mathrm{~A} / \mathrm{cm}^{2}$.

Detailed explanation on this is elaborated later in the following discussions.

A quantitative description on how the current density is distributed along the gas channel is shown in Fig. 5. Here, three locations along channel are taken for comparison, namely the inlet, halfway through the channel (middle), and exit. Figure 5 (a) shows spatial comparison of anode current density distribution at catalyst layer/membrane interface at $70^{\circ} \mathrm{C}$ using a nominal current density value of $0.5 \mathrm{~A} / \mathrm{cm}^{2}$. Under channel, the current density shows a decreasing profile towards exit. From Fig. 2, the anode overpotential at $0.5 \mathrm{~A} / \mathrm{cm}^{2}$ is ca. $0.35 \mathrm{~V}$, which suggest that an onset of COR might have been reached at this temperature, but at a very low rate. Therefore most of the sites under channel remain blocked with CO-ad, lowering the rate of HOR. Under the ribs, the current density is found to be increasing along the reactant flow, since more $\mathrm{H}$-ad needed for HOR is found where CO-ad is low. The highest current density is found at exit, with an increase of ca. 3.2\% from the nominal value. Figure 5 (b) on the other hand shows spatial comparison of anode current density distribution at catalyst layer/membrane interface under the same set of conditions, except the nominal current density is increased to $1.0 \mathrm{~A} / \mathrm{cm}^{2}$. It can be seen that under channel, similar to Fig. 5 (a), the current density decreases towards exit, but the inlet magnitude of current density is higher compared to the same location in Fig. 5 (a). From Fig. 2, the anode potential corresponding to this condition is ca. $0.5 \mathrm{~V}$, which is sufficiently high for $\mathrm{CO}$ oxidation reaction to occur. The high value of current density under channel at inlet here signifies increased HOR reaction rate due to $\mathrm{CO}$-ad being oxidized at high rate at this anode potential. Similar to the previous case, the highest magnitude of current density is found under the ribs at exit, with an increase of ca. $5.5 \%$ from the nominal value is predicted.

In the following figures, the effect of $\mathrm{CO}$ contamination towards transport of thermal energy in an operating PEMFC is presented and discussed. The sources of heat inside an operating cell are identified and modeled as the

(a)

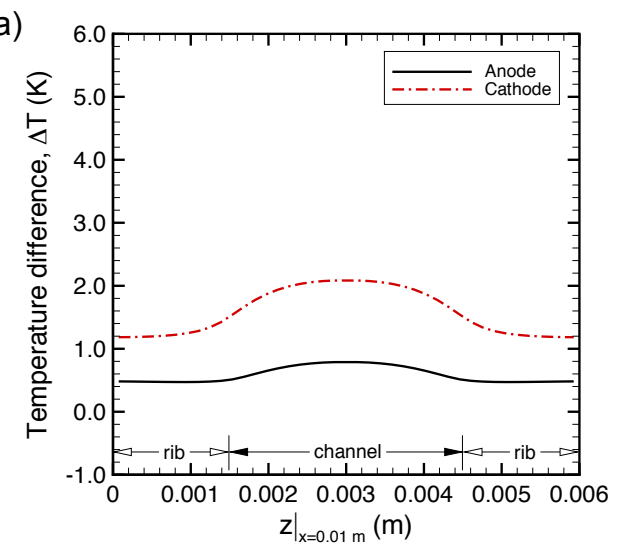

(b)

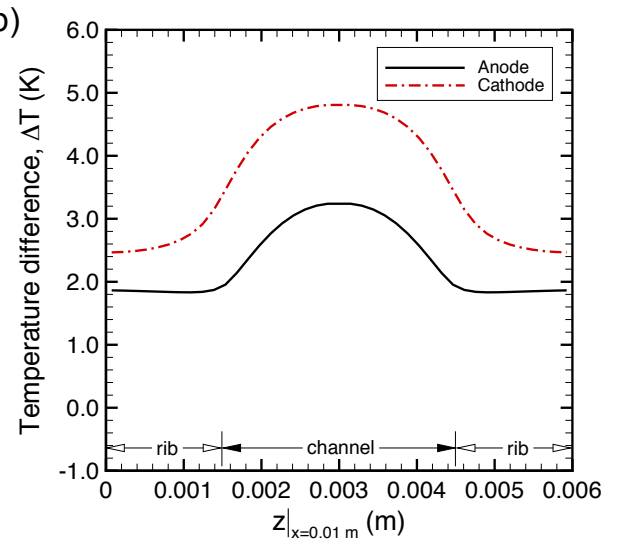

Fig. 6 Comparison of temperature distribution between anode and cathode catalyst layer/membrane interface halfway along the channel at $20 \mathrm{ppm}, 70^{\circ} \mathrm{C}$, and current densities of (a) $0.5 \mathrm{~A} / \mathrm{cm}^{2}$, and (b) $1.0 \mathrm{~A} / \mathrm{cm}^{2}$. 
(a)

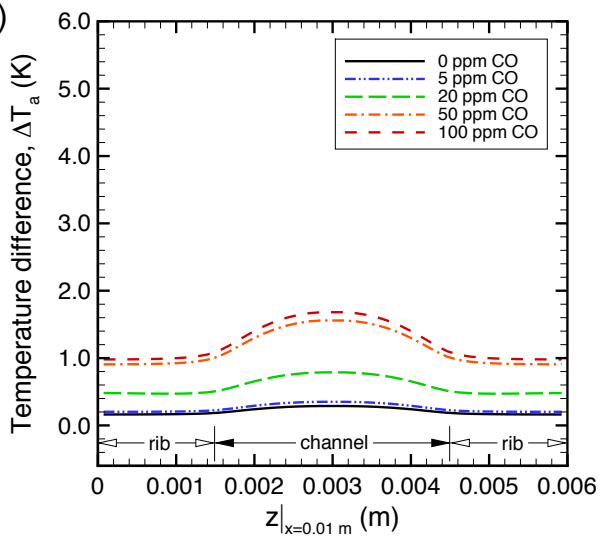

(b)

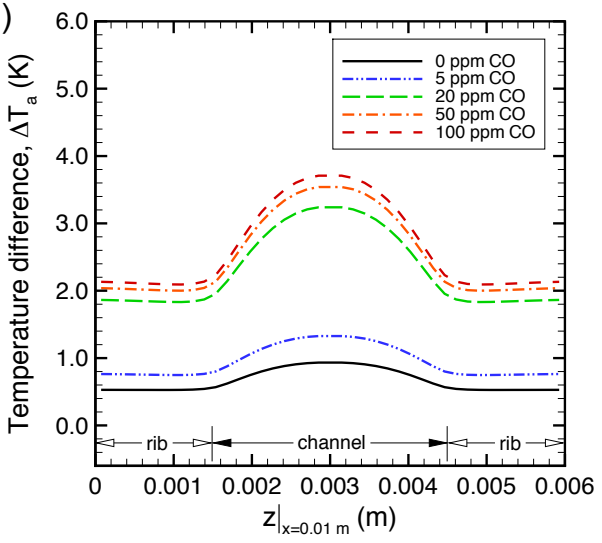

Fig. 7 Temperature distribution at the anode catalyst layer/membrane interface with variation of bulk $\mathrm{CO}$ concentration at $70^{\circ} \mathrm{C}$ and current densities of (a) $0.5 \mathrm{~A} / \mathrm{cm}^{2}$, and (b) $1.0 \mathrm{~A} / \mathrm{cm}^{2}$ at location halfway along the channel.

entropy change from the electrochemical reaction in the catalyst layers, irreversible exothermic electrode polarization loss and Joule heating from the solid phases of carbon and ionomer. Both anode and cathode catalyst layers release heat due to these sources. Figure 6 shows the highest temperature is found to be directly under channel at the cathode catalyst layer surface, due to higher entropy change and electrode polarization compared to anode catalyst layer. The generated heat is then transported towards the ribs, which acts as a sink through the porous GDL by a mixed conduction-convection mechanism in the solid and fluid phases, respectively. This results to a relatively lower temperature zone under the ribs in the porous GDL. As shown in Fig. 6 (a) for $0.5 \mathrm{~A} / \mathrm{cm}^{2}$ current density, the cathode catalyst layer registered ca. $1.5^{\circ} \mathrm{C}$ higher temperature than its anode counterpart. This difference in magnitude is aggravated when the current density is increased to $1.0 \mathrm{~A} / \mathrm{cm}^{2}$, shown in Fig. 6 (b) to be ca. $2^{\circ} \mathrm{C}$, where the increased reaction rate increased the irreversible heat generation due to polarization of the electrode. The region under the ribs for anode catalyst layer showed an inflection in temperature due to increased magnitude of current density here caused by larger amount of $\mathrm{H}-\mathrm{ad}$. By this figure, the anode catalyst layer is found to have a significant increase in its temperature, due to the presence of CO-ad leads to an increase in its polarization. How much influence does this have on the thermal energy characteristics on an operating cell is worth investigating.

The plots to further investigate the effect of bulk $\mathrm{CO}$ concentration in the cell towards anode catalyst layer surface spatial distribution of temperature are shown in Fig. 7. From Fig. 7 (a) it can be seen that at the same cell temperature and current density, the anode catalyst layer temperature increases with bulk $\mathrm{CO}$ concentration. For the cases investigated here (high cell temperature, intermediate magnitude of current density), a bulk CO concentration of 100 ppm will increase the anode catalyst layer temperature of ca. $2^{\circ} \mathrm{C}$ at most under the channel. Figure 7 (b) shows an increase of current density at the same temperature will exacerbate the rise in temperature at the same location, now to about ca. $4^{\circ} \mathrm{C}$ rise at most is found under channel. This is almost comparable to the increase of temperature experienced by the cathode catalyst layer, which is normally known to be the major source of heat in an operating cell. This is due to the fact that the anode polarization is higher with increase of CO-ad, and this significantly increases its temperature. The rise in anode electrode temperature with bulk CO concentration is however, not gradual due to the occurrence of COR alleviates the rise in anode overpotential. The significant rise in electrode temperature increases the possibility of dehydration in the membrane electrode assembly. In a CO-contaminated PEMFC, both electrodes are shown in this study to have substantial local rise in temperature. With the membrane sandwiched in between, it will be forced to operate at consistently high temperature, reducing its water diffusivity, hydration and its ionic conductivity. Furthermore, the elevated temperature at anode electrode will also cause local dehydration due to water evaporation in the pores that will affect water uptake into the membrane, particularly at high current density operation. In general, since the durability of a polymer electrolyte membrane reduces with decreasing hydration (Perry, et al., 2009), in tandem with $\mathrm{CO}$ contamination on the electrocatalyst, long-term performance of the cell is substantially compromised.

\section{Conclusion}

An investigation on the effects of $\mathrm{CO}$ contamination towards distribution of chemical species of $\mathrm{H}_{2}$ and $\mathrm{CO}$, 
surface coverage of competitively adsorbed $\mathrm{H}-\mathrm{ad}$ and $\mathrm{CO}-\mathrm{ad}$, as well as current density and temperature at membrane/CL interface inside a PEMFC has been made using a model that bridges micro-scale kinetics and macro-scale transport phenomena. Results show that a high local anode current density is predicted at the region under the ribs near exit due to CO-ad blocking under-channel Pt sites. Results also show that presence of CO-ad on the anode catalyst surface will increase anode catalyst layer temperature during operation to an extent comparable to the cathode electrocatalyst. A substantial increase in the anode catalyst layer temperature may lead to dehydration of the membrane and may reduce its durability in tandem with $\mathrm{CO}$ contamination. The increase in anode catalyst layer temperature will be aggravated in a simultaneous operation at high concentration of $\mathrm{CO}$ contamination and high current density.

\section{References}

Baschuk, J. J. and Li. X., Modelling CO poisoning and $\mathrm{O}_{2}$ bleeding in a PEM fuel cell anode, International Journal of Energy Research, Vol. 27 (2003), pp. 1095-1116.

Bhatia, K. K. and Wang, C-Y., Transient carbon monoxide poisoning of a polymer electrolyte fuel cell operating on diluted hydrogen feed, Electrochimica Acta, Vol. 49 (2004), pp. 2333-2341.

Camara, G. A., Ticianelli, E. A., Mukerjee, S., Lee, S. J. and McBreen, J., The CO poisoning mechanism of the hydrogen oxidation reaction in proton exchange membrane fuel cells, Journal of The Electrochemical Society, Vol. 149, No. 6 (2002), pp. A748-A53.

Gilman, S., The mechanism of electrochemical oxidation of carbon monoxide and methanol on platinum: II. The 'Reactant-pair' mechanism for electrochemical oxidation of carbon monoxide and methanol, The Journal of Physical Chemistry, Vol. 68, No. 1 (1964), pp. 70-80.

Gottesfeld, S. and Pafford, J., A new approach to the problem of carbon monoxide poisoning in fuel cells operating at low temperatures, Journal of The Electrochemical Society, Vol. 135, No. 10 (1988), pp. 2651-2652.

Gurau, V., Liu, H. and Kakac, S., Two-dimensional model for proton exchange membrane fuel cells, AIChE Journal, Vol. 44, No.11 (1998), pp. 2410-2422.

Hasmady, S., Hatakeyama, T., Wacker, M. P., Fushinobu, K. and Okazaki, K., Treatment of heterogeneous electrocatalysis in modeling transport-reaction phenomena in PEFCs, Thermal Science \& Engineering, Vol. 17 (2009), pp. 147-156.

Hasmady, S. and Fushinobu, K., Inclusion of surface heterogeneity in bridging PEM fuel cell electrode contamination kinetics and transport via a competitive Langmuir-Freundlich isotherm, Journal of Solid State Electrochemistry, In Press (2014), DOI 10.1007/s10008-014-2521-0.

Hauptmann, W., Votsmeiera, M., Vogel, H. and Vlachos, D. G., Modeling the simultaneous oxidation of $\mathrm{CO}_{\text {and }} \mathrm{H}_{2}$ on $\mathrm{Pt}$ - Promoting effect of $\mathrm{H}_{2}$ on the CO-light-off, Applied Catalysis A: General, Vol. 397 (2011), pp. $174-182$.

Ju, H., Lee, K. S. and Um, S., Multi-dimensional modeling of CO poisoning effects on proton exchange membrane fuel cells (PEMFCs), Journal of Mechanical Science and Technology, Vol. 22 (2008), pp. 991-998.

Kawaguchi, T., Sugimoto, W., Murakami, Y. and Takasu, Y., Temperature dependence of the oxidation of carbon monoxide on carbon supported Pt, Ru, and PtRu, Electrochemistry Communications, Vol. 6 (2004), pp. $480-483$.

Lee, S. J., Mukerjee, S., Ticianelli, E. A. and McBreen, J., Electrocatalysis of CO tolerance in hydrogen oxidation reaction in PEM fuel cells, Electrochimica Acta, Vol. 44 (1999), pp. 3283-3293.

Li, X., Principles of Fuel Cells (2006), Taylor \& Francis.

Masuda, M., Hydrogen-based Integrated Energy System for Building Equipment (2003), PhD Thesis, Tokyo Institute of Technology, Japan (in Japanese).

Oetjen, H. F., Schmidt, V. M., Stimming, U. and Trila, F., Performance data of a proton exchange membrane fuel cell using $\mathrm{H}_{2} / \mathrm{CO}$ as fuel gas, Journal of The Electrochemical Society, Vol. 143, No. 12 (1996), pp. 3838-3842.

Perry, M. L., Darling, R. M., Kandoi, S., Patterson, T. W. and Reiser, C., Operating requirements for durable polymer-electrolyte fuel cell stacks, in: Büchi, et al. (Eds.), Polymer Electrolyte Fuel Cell Durability (2009), Springer Science.

Sips, R., On the structure of a catalyst surface, The Journal of Chemical Physics, Vol. 16, No. 5 (1948), pp. $490-495$.

Springer, T. E., Zawodzinski, T. A. and Gottesfeld, S., Polymer electrolyte fuel cell model, Journal of The Electrochemical Society, Vol. 138, No. 8 (1991), pp. 2334-2342.

Springer, T. E., Rockward, T., Zawodzinski, T. A. and Gottesfeld, S., Model for polymer electrolyte fuel cell operation 
on reformate feed: Effects of $\mathrm{CO}, \mathrm{H}_{2}$ dilution, and high fuel utilization, Journal of The Electrochemical Society, Vol. 148, No. 1 (2001), pp. A11-A23.

Zamel, N., Transport Properties of the Gas Diffusion Layer of PEM Fuel Cells (2011), PhD Thesis, University of Waterloo, Canada.

Zhdanov, V. P. and Kasemo, B., Kinetics of electrochemical $\mathrm{O}_{2}$ reduction on Pt, Electrochemistry Communications, Vol. 8 (2006), pp. 1132-1136.

Zhou, T. and Liu, H., A 3D model for PEM fuel cells operated on reformate, Journal of Power Sources, Vol. 138 (2004), pp. 101-110.

\section{Acknowledgements}

Part of this work was supported by the Grant-in-Aid for Scientific Research from MEXT/JSPS and Iwatani Foundation.

\section{Nomenclature}

\begin{tabular}{|c|c|c|c|}
\hline$a$ & water activity $[-]$ & $X$ & mole fraction \\
\hline$A$ & area $\left[\mathrm{m}^{2}\right]$ & $y_{\mathrm{M}}$ & membrane thickness $[\mathrm{m}]$ \\
\hline$A$ & pre-exponential factor $[/ \mathrm{s}]$ & $x, y, z$ & Cartesian coordinates $[\mathrm{m}]$ \\
\hline$c$ & concentration $\left[\mathrm{mol} / \mathrm{m}^{3}\right]$ & & \\
\hline$c_{p}$ & specific heat $[\mathrm{J} /(\mathrm{kg} \cdot \mathrm{K})]$ or $[\mathrm{J} /(\mathrm{mol} \cdot \mathrm{K})]$ & \multicolumn{2}{|c|}{ Greek symbols } \\
\hline$D$ & diffusion coefficient $\left[\mathrm{m}^{2} / \mathrm{s}\right]$ & $\Gamma$ & site density $\left[\mathrm{mol} / \mathrm{m}^{2}\right]$ \\
\hline$E$ & electrode potential [V] & $\alpha$ & symmetry coefficient \\
\hline$\tilde{E}_{\mathrm{a}}$ & activation energy $[\mathrm{J} / \mathrm{mol}]$ & $\beta$ & temperature exponent $[\mathrm{K}]$ \\
\hline$F$ & Faraday's constant, $96485 \mathrm{C} / \mathrm{mol}$ & $\varepsilon$ & porosity \\
\hline$h$ & heterogeneity index $[-]$ & $\eta$ & overpotential [V] \\
\hline$i$ & local current density (geometric area) $\left[\mathrm{A} / \mathrm{m}^{2}\right]$ & $\theta$ & surface coverage \\
\hline $\bar{i}$ & local current density $(\mathrm{Pt}$ area $)\left[\mathrm{A} / \mathrm{m}_{\mathrm{Pt}}^{2}\right]$ & $\lambda$ & hydration \\
\hline$k$ & thermal conductivity $[\mathrm{W} /(\mathrm{m} \cdot \mathrm{K})]$ & $\mu$ & dynamic viscosity $[\mathrm{Pa} \cdot \mathrm{s}]$ \\
\hline \multirow[t]{3}{*}{$k_{\mathrm{f}}$} & forward rate constant, & $\rho$ & density $\left[\mathrm{kg} / \mathrm{m}^{3}\right]$ \\
\hline & first order $\left[\mathrm{m}^{3} /(\mathrm{mol} \cdot \mathrm{s})\right]$ & $\tau$ & tortuosity \\
\hline & second order $\left[\mathrm{m}^{5} /\left(\mathrm{mol}^{2} \cdot \mathrm{s}\right)\right]$ & $\sigma$ & conductivity $[\mathrm{S} / \mathrm{m}]$ \\
\hline \multirow[t]{3}{*}{$k_{\mathrm{b}}$} & backward rate constant, & $\sigma_{1}$ & Tafel-step correction factor $[\mathrm{J} / \mathrm{mol}]$ \\
\hline & first order $[/ \mathrm{s}]$ & $\varphi$ & relative humidity $[\%]$ \\
\hline & second order $\left[\mathrm{m}^{2} /(\mathrm{mol} \cdot \mathrm{s})\right]$ & $\phi$ & local potential $[\mathrm{V}]$ \\
\hline \multirow[t]{3}{*}{$K$} & equilibrium constant & & \\
\hline & $\mathrm{H}, \mathrm{CO}$ and $\mathrm{H}_{2} \mathrm{O}$ adsorption $[/ \mathrm{kPa}]$ & \multicolumn{2}{|c|}{ Subscripts and superscripts } \\
\hline & $\mathrm{H}_{2} \mathrm{O}$ desorption $[\mathrm{kPa}]$ & $\bigcirc$ & standard (in potential) \\
\hline$L_{\mathrm{Pt}}$ & catalyst loading $\left[\mathrm{mg}_{\mathrm{Pt}} / \mathrm{cm}^{2}\right]$ & 0 & standard \\
\hline$m$ & reaction order & $\mathrm{a}$ & anode \\
\hline$M$ & molecular weight $[\mathrm{kg} / \mathrm{mol}]$ & $\mathrm{c}$ & cathode \\
\hline$P$ & pressure $[\mathrm{Pa}]$ & eff & effective \\
\hline$r_{\mathrm{f}}$ & roughness factor & geom & geometric \\
\hline$R$ & universal gas constant, $8.314 \mathrm{~J} /(\mathrm{mol} \cdot \mathrm{K})$ & $i, j$ & species $i$ or $j$ \\
\hline$R_{\text {ohmic }}$ & Ohmic resistance $\left[\Omega \cdot \mathrm{m}^{2}\right]$ & in & inlet \\
\hline$s$ & sticking coefficient & Lim & limiting \\
\hline$S$ & source term & $\mathrm{m}$ & gas mixture \\
\hline$\Delta S$ & entropy change, $[\mathrm{J} /(\mathrm{mol} \cdot \mathrm{K})]$ & $\mathrm{M}$ & ionomer phase \\
\hline$T$ & temperature $[\mathrm{K}]$ & rev & reversible \\
\hline$u$ & velocity $[\mathrm{m} / \mathrm{s}]$ & $\mathrm{s}$ & solid phase \\
\hline$\dot{\forall}$ & volume flow rate $\left[\mathrm{m}^{3} / \mathrm{s}\right]$ & sat & saturation \\
\hline
\end{tabular}

